\title{
Alternative Assessment Approaches in Primary English Language Classrooms
}

Pratistha Shrestha

\begin{abstract}
In recent years, the philosophy and implementation of alternative assessment in primary classrooms have become the center of discussion and debate in the educational sector among scholars, educators, and stakeholders in many countries including Nepal. This paper presents a study on the alternative assessment practices in primary English language classrooms based on a qualitative approach. The aim of this paper is to provide an overview of alternative assessment, the paradigm shift from traditional assessment to alternative assessment, and some insights on the practices of alternative assessment prevalent in the selected private schools in Kathmandu valley along with teachers' perceptions and challenges.
\end{abstract}

Key words: Alternative assessment; Traditional assessment; Performance assessment approach; Peer assessment; Self-assessment

\section{Introduction}

Currently there have been debates among the educators about the practicality and benefits of alternative approaches to assessment in English language teaching. A variety of labels have been used to distinguish alternative assessment approaches from standardized testing. Garcia and Pearson (1994) as cited in HuertaMacias (1995) include the following in their review of these labels: performance assessment, authentic assessment, portfolio assessment, informal assessment, situated or contextualized assessment and assessment by exhibition. They also state that alternative assessment consists of all those efforts that do not adhere to the traditional criteria of standardization, efficiency, costeffectiveness, objectivity and machine scorability.

Before considering the rationale behind the paradigm shift from traditional to alternative assessment practices, it's very important to distinguish the differences between them and the table below demonstrates such differences explicitly. (Bailey,1998, p. 207 as cited in Coombe \& Hubley, 2011). 
Table 1: Contrasting traditional and alternative assessment

\begin{tabular}{|l|l|}
\hline Traditional Assessment & Alternative Assessment \\
\hline One-shot tests & Continuous, longitudinal assessment \\
Indirect tests & Direct tests \\
Inauthentic tests & Authentic assessment \\
Individual projects & Group projects \\
No feedback provided to learners & Feedback provided to learners \\
Timed exams & Untimed exams \\
De-contextualized test tasks & Contextualized test tasks \\
Norm-referenced score interpretation & Criterion-referenced score interpretation \\
Standardized tests & Classroom-based tests \\
\hline
\end{tabular}

Source: Bailey, 1998, p. 207 as cited in Coombe \& Hubley, 2011.

Hence, alternative assessment focuses more on higher-level thinking skills rather than just the scores. Moreover, it is closely intertwined with classroom instruction which eventually helps teachers to gauge students' progress in real classroom context using multiple indicators.

Alternative assessment came about as a reaction to more traditional assessments. One of the major dissatisfactions was that English language teachers were encouraged to utilize communicative approaches but assessed their students with traditional paper-pencil tests (Puppin, 2007). As a result, this had encouraged teachers to view teaching and assessing in isolation rather than reflections of a real classroom setting. The other dissatisfactions raised (e.g. Lafi, 2002) were tests take up a lot of teaching time and were not always fair as they do not account for individual differences (multiple intelligences / different learning styles, etc.). In addition, many traditional tests did not provide teachers with or had not developed level descriptors, which are concise statements describing the character of a minimally acceptable performance of an oral or written presentation (McNamara, 2000 as cited in Puppin, 2007). Through traditional tests, students rarely got to know the reasons behind their failure and success.

Douglas (2010) and Brown and Hudson (1998) clarified that the proponents of alternative assessment argued for assessments that were extensions of normal classroom learning activities familiar to the learners, requiring learners to produce language in natural contexts, and in a culturally sensitive way. In this regard, Law and Eckes (2007) advocated that alternative assessments allow teachers to look for answers if one method does not give us enough information. To illustrate their views further, they explained that if the 
student cannot perform a task on a particular day, teachers have the time and opportunity to discover whether the student can perform the task at a different time, in a different situation, perhaps with different instructions or media. In short, alternative assessment approaches cater to the individual needs of the students and enhance holistic development in an engaging English language classroom environment.

\section{Rationale of the study}

There has been a growing concern for improving the quality of achievement of all learners at elementary and secondary level through continuous and comprehensive evaluation system in Nepal (Higher Secondary Education Board, 2011). Thus, schools have started implementing and advocating alternative assessment practices other than standardized tests in primary English classrooms. However, only a carefully planned alternative assessment system can help students to be autonomous learners, and teachers to scaffold students' learning. In addition, Curriculum Development Centre [CDC], (2008) has stated that

Students' learning level will be determined through a formative evaluation system at the primary level. The main aim of formative evaluation is to improve students' learning level. From this teachers would be able to provide more and more learning opportunities on the basis of students' learning achievements. Students' portfolio will be maintained from grades 1 to 3. The portfolio will be updated according to students' class work, project work, behavioral change, attendance etc. Schools should inform parents about the subject matter taught and students' progress, which will also be recorded in the portfolio. Class work will be emphasized rather than homework at this level (CDC, 2008, p. 10).

Thus, the national primary curriculum of English has acknowledged and advocated for a continuous assessment system for students' overall personal growth. Ironically, this system hasn't been the crusade of our national assessment system yet and has been limited to the policy only. In Nepal, even today the most commonly used method in deciding children's level of understanding is paper-pencil tests, which is a bitter reality.

In the context of Nepal, it has been a challenge to implement continuous assessment system in real classrooms because of frequent political instability, geographical diversities, religious beliefs and orthodox practices (Higher Secondary Education Board [HSEB], 2011). There are reports that give evidence of the negative impact of examination system. According to Parajuli (2003), “There are still nearly twenty percent of the primary age group children out of school either dropout or repeat classes. The quality of education has also not improved. One of the main reasons given is the defective assessment system". (p. 1). In addition, Khaniya (2005) has reasoned that a 3-hour examination cannot test students' other aspects- physical, social, intellectual, emotional which have also 
contributed to their development. Hence, we can't get a full picture of a student's language skills from a single test score.

To illustrate the empirical effectiveness of alternative assessment, some insights from the research studies are presented which include Alausa's (1996) research which has evaluated the meaning of continuous assessment, its advantages and the problems that could be encountered in its practical application in Arandis. This study concluded that such assessment could play a vital role in diagnosing and remediating areas of learners' weaknesses if properly anchored in what occurs in classrooms, addressing the learning problems on time as well as placing teachers at the center of all performance-assessment activities. The study has explored its disadvantages in terms of teachers' skills in test construction and administration, and their attitudes toward the continuous assessment approach and record-keeping, as well as the availability of valid and reliable tests used in all schools.

Bolyard (2003) researched on "Linking Continuous Assessment and Teacher Development: Evaluating a Model of Continuous Assessment for Primary Schools in Malawi". This research has conducted a feasibility study on the impact of continuous assessment on primary school pupils' achievement. The model integrated teacher training sessions into its implementation process. The outcomes of this research were that continuous assessment model has transformed their bare classrooms into stimulating learning environments with math manipulatives, sentence boards, rainbow charts, and other materials. In some cases, pupils come to school early to spend time working with the objects; additionally, significant enhancement in parental and community involvement in the continuous assessment schools occurs.

Interestingly, Parajuli (2003) conducted a similar study based on a pilot program on Continuous Assessment System (CAS) which was introduced in the five Compulsory Primary Education districts i.e. Illam, Chitwan , Syangja, Surkhet and Kanchanpur beginning in the school year 2000/01. The research topic was 'Effect of CAS on Students' Achievement, Dropouts and Attendance'. The pilot program first started with grade 1 and in subsequent years with grades 2 and 3 . Hence, the cycle of CAS was completed in the academic year 2002/2003. The CAS program included teacher training, materials development and distribution, management of students' evaluation, and evaluation. The research findings revealed that the teachers regarded the CAS as extra burden for them. The teachers were confused regarding the use of the CAS materials and faced problems in matching the lesson goals with that of the students' progress reports. Most importantly, teachers used the CAS information only for upgrading purposes, not for formative purposes or for the improvement of instruction. The analysis of portfolio records of two districts Chitwan and Surkhet did not show any fixed trend regarding students' rating. Besides, there was no co-relation between portfolio rating and achievement scores. The study revealed 
that the achievement trend of the CAS students was lower than the non-CAS students. As a result, parents had indifferent feelings towards their children's learning.

To summarize, the reports and research based on assessment in government schools in Nepal have revealed the negative aspects of examination and failure in the successful implementation of the alternative assessment concept in the classrooms. However, the recent development of assessment practices in English language classrooms in private schools in Kathmandu has not yet been explored. Thus, to make the paper more specific it sought to answer the following research questions:

1) What alternative approaches are practised in private schools to assess primary school students' English language skills?

2) How do English language teachers perceive the alternative assessment approaches?

3) What challenges do English language teachers face while implementing the alternative assessment approaches?

During the research, the following question emerged and further guided the study:

1) What factors need to be considered while implementing the alternative assessment approaches in primary English language classrooms?

\section{Methodological consideration}

I have adapted Flick's (2006) essential features of qualitative research in which I have looked for appropriateness of methods and theories, incorporated perspectives of the participants and their diversity, along with reflectivity of the researcher and the research.

I have purposively selected the six private schools of Kathmandu valley on the basis of their experience in implementing alternative approaches to assessment in the course of their dayto-day teaching.

In order to obtain diverse individual opinions and to capture participants' lived experiences, I adopted narrative design and open ended interviewing methods. Narratives are very influential idea for recollecting one's past experiences. Hermanns (1995) has characterized a narrative as follows:

First the initial situation is outlined ('how everything started'), then the events relevant to the narrative are selected from the whole host of experiences and presented as a coherent progression of events ('how things developed'), and finally the situation at the end of the development is presented ('what became') (Hermanns,1995 as cited in Flick, 2006, p.172).

Thus, in my research, written narrative was used for collecting data where the participants narrated their initial learning and teaching experiences along with their professional growth, perceptions regarding the appropriateness and practicality of their own assessment practices. This 
helped them to share their own stories related to assessment practices rather than being influenced by the research objectives. In the initial phase, I selected five teachers from each of the six school to write narrative journals. Then I chose only one participant from each school based on their rich and diverse background for my further study (APPENDIX A). Cohen, Manion and Morison (2008) advocate that five to six participants are enough in qualitative research.

Richards (2003) states that interviewing is never really an "answer" to anything; it is a journey within a journey. Thus, I conducted multiple interviews with each of the participants to explore their experiences in-depth rather than just confirming the pre-existed truth or reality on the presented issue.

This study was delimited to the selected private schools in Kathmandu that maintained international teaching standards and followed progressive education philosophy compared to the average private schools. Therefore, they do not necessarily represent the majority of private schools in Kathmandu.

\section{Analysis and interpretation}

The findings collected from the obtained data analysis are categorized under four themes: alternative assessment approaches in English classrooms; teachers' attitudes towards alternative assessment approaches; challenges implementing alternative assessment approaches; and factors affecting the implementation of alternative assessment approaches with reference to the research questions. Excerpts from the respondents' responses are included to have the respondents' own say on the research issues.

\section{Alternative assessment approaches in English classrooms}

This theme highlights the core findings of different alternative assessment approaches practised in the private schools to assess students' English language skills at the primary level.

\section{Performance assessment approach}

All the respondents shared that their assessment was highly influenced by students' daily "performances"during different classroom activities.

\section{Project work}

One of the most familiar classroom activities among all the respondents was involving and assessing students' project work. Freeman and Lewis (2005) define the essence of a project as a move, beyond the immediate educational context, from "the classroom" into "real life" and student pro-activity. In this regard, Respondent 3 highlighted:

Last time I gave project work from my lesson "In the Tea Shop" which was based on the restaurant visit. They went to visit the restaurant with their parents and asked questions to the waiters, observed the setting of the restaurant and menu cards. Afterwards they created their own menu card and brochure for their imaginary restaurant. Here, project work comes as a process. 
The first sentence of this quotation points out important issues of incorporating students' notable experiences into real classroom context and English language across the curriculum. Moreover, she has shown the strategy to meet the learning objectives of a lesson by involving families in the learning process and assigning real life tasks like systematic observation, note taking skills and interviewing skills in language learning. This practice was also used by Respondent 1, Respondent 4, Respondent 5 and Respondent 6 . The respondents' quotes depicted that they were aware of the concept of bridging the gap between language study and language use through project works as indicated by Larsen-Freeman (2010). An understanding and uniformity existed among the respondents while sharing about the purpose and classroom activities illustrations regarding project works.

\section{Co-operative learning as alternative assessment}

Respondents consistently responded with diverse classroom activities that incorporated group or pair work. They viewed group work as an integral part of their classroom activities as it helped to make the class inclusive and build social, emotional, and leadership skills along with English language learning.

\section{Encouraging and assessing reading: beyond the curriculum}

Regarding assessing students' reading skill, respondents reported that they encouraged students to develop reading as a habit through various class activities like read aloud, guided reading, individual reading, check out books from the school library, giving book talk and maintaining reading logs. Respondent 4, Respondent 5, and Respondent 6 had a book corner in their class as part of their school culture to encourage reading.

\section{Journal writing}

Another common alternative assessment practice among the respondents was journal writing as suggested by Ghaith (2002) and HuertaMacias (1995). Respondent 2 encouraged her students to write everyday in a journal while the other preferred assigning occasional journal writing tasks. Except Respondent 2, other Respondents avoided correcting grammatical errors in students' journal and regarded it as a medium to know each child personally. Instead of correcting students' grammatical errors, Respondent 4, Respondent 5 and Respondent 6 wrote their comments on how they felt reading students' journals in their journal notebook which was in line with Whole Language Approach (see Richards and Rodgers, 2002; Larsen-Freeman, 2010).

\section{Integrating oral language assessment in everyday interaction}

Students' speaking skills were assessed through everyday classroom interaction like drama, group discussion, poetry recitation, retelling stories, debate, questioning skills, field trips and presentations. Among these, the morning meeting was the most common school practice for Respondent 3, Respondent 4, Respondent 5 and 
Respondent 6 to enhance and assess students' speaking skills. Those meetings were used to encourage students to share their ideas, feelings and emotions without hesitation.

\section{Peer assessment}

Among six respondents, three respondents were found to be familiar with peer assessment. They used peer assessment in a variety of student activities viz. group work, presentations, making questions based on three levels (recalling, reasoning and relating in real life contexts), written work and giving feedback. Their experiences gave evidence on how peer assessment engages the whole class in high level thinking through the ownership of the assessment process as mentioned in Spendlove (2011). By involving students in giving feedback, they helped both the feedback receiver and the feedback giver to understand their own learning objectives; internalize the learning goals and progress indicators in the context of someone else's work as suggested by Heritage (2011).

\section{Self-assessment}

Respondent 6 was the only respondent who encouraged self-assessment in her English language class. Her selfassessment practice was usually based on equipping students' with editing skills. To illustrate her views further, she described her self-assessment practice:

While working on folders or projects, we give deadlines to finish their work and ensure they learn to edit their own work. Moreover, they feel that it's not just teachers' work but to make them aware of they are capable of doing things and helping them how they overlook things. I feel all kids have potential to do so it's just how we help them to find their ways.

This quote depicted the crucial role of teachers in involving their students in identifying and addressing their own diverse needs as well as strengths. While involving students in self-assessment, she didn't encourage them to give themselves grades, in line with Andrade (2011). Respondent 6 explained that self-assessment enabled students to develop mutual understanding, shared responsibility for their learning, selfmotivation and enhanced cognitive level as suggested by Shepard et al. (2005).

\section{Portfolio approach}

Portfolio approach was another frequent assessment practice among the respondents in their English classes. For some respondents, they weren't aware of the term "portfolio" but they had each student's personal file. The contents collected in the portfolio varied from respondent to respondent. Respondent 1 explained, "We maintain each student's personal files where we keep their test papers, reading record of English story books, creative writing pieces in English language and term wise report cards". Correspondingly, Respondent 4 and Respondent 5 opined that teachers maintain each student's file with their everyday home assignments, and class activities. One common thing in these examples was that the portfolio served as just a collection of students' work that revealed both the capacity and the progress of a learner as suggested by Cameron (2001). In contrast, Respondent 6 stated that her students' portfolio included their "fair" works 
which were later exhibited to parents and school administrators, which is in line with O'Malley and Pierce (1996).

\section{Rubrics}

Using rubrics as one of the strategies of assessing students' English language learning performance was common among the respondents. Respondent 2 stated:

Students get very interested to know why they got $A+, B$, what is the meaning of $B+, B$. In grade 4 , once I gave $B$ to a student, he went home and said to his mother that he must get A. Then I explained him about his mistakes and how he could improve. After the discussion, the boy was convinced and promised to improve those areas.

Here her experience reflected that the teachers need to ensure the learner understands what quality looks like and challenges misconception about what might or might not represent good outcomes from the learning (Spendlove, 2011). Through Respondent 2's incident, it is evident that once the expectations are communicated, students are more likely to perform better with high motivation and with a positive attitude to learn, improve and reach the set goals.

While Respondent 2 and Respondent 6 were sharing their teacher made rubrics, Respondent 3 advocated involving students in making decision about their performance regardless of their age. Following Shepard et al. (2005), she seemed to suggest that rubrics help students to develop metacognitive awareness of what they need to attend to and in learning the rules and forms of a discipline, not just a means to justify grading. As a result, there was mutual trust among teachers and students as well as fairness in assessment which eventually empowered students to be autonomous learners.

\section{Conference assessment approach}

The role of conferences in English classroom was very evident among the respondents. Respondent 3 expressed this need in the following manner, "I talk with the students individually and help them to do correction or their incomplete works". This practice was carried out by Respondent 1, Respondent 2, Respondent 3, Respondent 4 and Respondent 5. In addition, Respondent 6 emphasized the emotional needs of the children while communicating with them besides focusing on their academic needs. She acknowledged the fact that students have potential and can learn the same at different times if not at the same time. Her views of fostering students' reflection on their own learning process, helping students to develop better selfimages, eliciting language performances and gathering information about students were in line with Brown and Hudson (1998).

\section{Feedback}

Another notable alternative assessment that had influenced the respondents' English teaching was regular feedback to students. Respondent 4, Respondent 5 and Respondent 6 mentioned that they needed to prepare individual written feedback based on students' performance in English class to include in the report card every term. Respondent 4 explained the features of her written feedback: 
Teachers write comments about each child including what the child has achieved, areas for improvement/future learning, what parents can do at home and what the school will do to support the progress? for each subject.

Her experiences showed that the feedback assisted her students to understand their current learning status and provided hints, suggestions or cues for them to act on (Heritage, 2011). This was identical to Respondent 5 and Respondent 6's classroom practice. To illustrate her views regarding written feedback, Respondent 4 shared a sample of it:

Seema enjoyed working on the project of 'Charlotte's Web' and has written a detailed literary journal. Seema will further benefit by reading books as this will help her to improve her vocabulary and express her thoughts clearly.

In the above sample, the feedback is concise and specific, offers a clear idea of what to do next with the student and helps parents as well as the student to feel good about their capabilities as suggested by Law and Eckes (2007).

\section{Teachers' attitude towards alternative assessment approaches}

Respondents were positive about the alternative assessment approaches. Respondent 2 used the metaphor "a 360 degree approach" to explain how the teachers have to observe their students all the time and give them continuous feedback for their learning which happens in school, at home and other places they visit. Likewise, Respondent 3 shared:
I am positive with my assessment practices because I get a clear picture about each child. I keep the record, interact and involve them in all activities. That helps to identify each child's level and work on how to counsel, how to deal with it, what are the areas we have to focus on for next planning.

Her statement constructed various perceptions related to alternative assessment approaches like the importance of recognizing each student's performance level, planning interventions to address students' needs and creating lessons accordingly. In addition, Respondent 4 emphasized helping academically strong students as well to maintain the whole classroom standard by bringing students' different levels of capacities to a level higher than they are in.

Apart from identifying students, the alternative assessment practices also provide future reference for teachers to understand the student's background. In addition, Respondent 5 endorsed that while bringing forth the creativity of students, it enabled them to understand and relate their knowledge to their daily life and experiences. Correspondingly, Respondent 3 felt that her students were confident, creative and sincere in their studies. Similarly, Respondent 6 found that alternative assessment helped teachers to create a conducive learning environment where students could learn and discover a wide range of language skills, life skills and social skills. 
Respondents felt that alternative assessment practices provided them with strong evidence regarding their own teaching and learning practices. Respondent 5 shared that if a child didn't understand, then teachers could always revise their planning instead of blaming students for being inattentive or irresponsible towards learning. In a nutshell, respondents displayed enthusiastic and positive attitudes towards alternative assessment.

\section{Challenges of implementing alternative assessment approaches}

Respondents shared different aspects of alternative assessment practices which were challenging for them. Respondent 1 found assessing and maintaining records of individual oral reading difficult. Respondent 4 felt difficult to balance project works and lessons. Respondent 2 and Respondent 5, who had more than a decade in traditional teaching, found it tricky to adapt and adjust themselves in the alternative assessment practices. Respondents felt addressing the different needs of each student was demanding.

Despite informing and involving parents in the assessment practices, respondents still felt it challenging to change some parents' attitudes towards test scores and grades. Strikingly, Respondent 2, Respondent 4, Respondent 5 and Respondent 6 linked the issue of parental anxieties and doubts to the effectiveness of alternative assessment approaches and concerns regarding test scores with Nepal's National education policy. Notably, some respondents pointed out that the system of District Level Exam at grade 8 and School Leaving Exam at grade 10 have influenced parents' anxieties to some extent. Research has shown that assessment, as it occurs in schools, is deeply social and personal (Johnson et al, 1995 as cited in Black \& William, 1998). The majority of schools still rely solely on test scores and the use of alternative assessment methods comes out as a radical approach for most of the parents who themselves were raised on a more traditional evaluation methods. The respondents asserted that to overcome such issues, communication is at the centre of their school philosophy.

As a senior teacher, Respondent 6 had encountered many teachers who faced difficulty to mention their everyday observation in written form in her school. She further illustrated, "Teachers usually tend to generalize the comments and write same comments for everyone". She seemed to agree with Higgins (2011) who pointed out that the key to making the feedback effective is highly based on how this is given.

\section{Factors affecting the implementation of alternative assessment}

\section{School culture}

All the respondents viewed school culture as a crucial agent that had an overall impact on the whole assessment process. The Respondents' responses had shown that expatriates had a very influential role in establishing the assessment practices in schools. Among

$158 \quad$ Journal of NELTA, Vol 18 No. 1-2, $\quad$ December 2013 
six schools, four schools had hired expatriates to introduce the school's current assessment practices from the establishment of the school. These expatriates helped in designing curriculum, alternative assessment practices, conducting training and mentoring teachers in the schools. Besides the contribution of the expatriates, the schools also had qualified subject wise coordinators and principals from whom the teachers could get support instantly through weekly and monthly meetings. The literature has acknowledged this truth and stated "If teaching is to change then teachers need support to do so and increasingly schools are identifying coaches who can help colleagues develop their teaching repertoire and philosophy to engage with assessment for learning principles" (Spendlove, 2011). The respondents' experiences showed that continuing professional development was kept at the centre of assessment practices in English classrooms. Moreover, new teachers were not left alone in the classroom, which eventually influenced the alternative assessment practices in the school. All the respondents acknowledged and appreciated the initial support that they got from their colleagues in their early years of teaching. Black, Harrison, Lee, Marshall and William (2002) have insisted that support from colleagues is particularly important in overcoming those initial uncertainties when engaging in the risky business of changing the culture and expectations in the classroom.

\section{Time management}

Time management is very important for the successful implementation of the alternative assessment practices in English class. Respondent 1 said, "I teach 25 periods in a week. We get free periods on the basis of extracurricular classes like swimming, dance, physical education, music, art and crafts, computer, library which are scheduled on the daily routine. Sometimes I even come to school at weekends, take my work home to finish on time". Respondent 2 shared, "In one day, I get two periods off, sometimes three and sometimes one only. I also take the record books at home". Respondent 3, Respondent 4, Respondent 5 and Respondent 6 even had to stay after school for one hour to work on their lesson plans, evaluate assignments and maintain students' records. Team teaching was another significant practice among Respondent 3, Respondent 4, Respondent 5 and Respondent 6 that had direct influence in time management. In sum, it is clear that teachers need enough time to prepare their lessons so that they could incorporate assessment within the teaching instructions carefully.

\section{Flexible curriculum}

It was encouraging to see all the respondents planning their lessons ahead in a systematic and organized way. Respondent 2 and Respondent 3 shared that their school administration permitted teachers to make necessary changes instead of pressurizing them to follow the prescribed textbook. Respondent 5 maintained," We don't follow any particular textbook. We have 
our school's curriculum so we create our own worksheets, activities using internet and other resource materials. It's flexible but flexibility doesn't mean that we can do whatever we want. We have yearly plan, term-wise plan, monthly plan, weekly plan and lesson plan. So we have a framework of our planning". This practice was identical to Respondent 1, Respondent 4 and Respondent 6's.

\section{Involving families}

The respondents shared how parents were informed and involved in students' learning process. 'Curriculum Evening' was a common practice among all the respondents except Respondent 2. In Curriculum Evening, parents were invited in the beginning of every school year where teachers informed parents about their curriculum, explained class activities, assessment process and how parents could get involved in their children's learning process. Since her school changed the alternative assessment practice after a long tradition of traditional assessment practices, Respondent 2 shared that they first sent a circular explaining about the new assessment practices and later received it with parents' signatures on it. Then the parents were called at school to explain to them about the school's new assessment practices. Here, the school took the consent of parents ahead of making the academic changes. Thus, it reveals that communication among families and schools are very important for students' learning. The common practices among the respondents were writing a message to parents in the students' diary, making phone calls and organizing an individual parent-teacher conference after each term. These practices were in line with HuertaMacias (1995) who advocated for the triangulation of data from three different sources- students, teachers and family- in alternative assessment for English as Second Language class.

\section{Conclusion and implications}

The findings indicated that though the respondents had used different terms like "Ongoing Assessment", "Continuous Assessment" and "Continuous and Comprehensive Evaluation", their classroom experiences reflected their clear understanding and confidence in adopting various alternative approaches. They focused on using different activities in the real classroom context to gauge students' performances (Huerta-Macias, 1995; Ghaith, 2002; Brown and Hudson, 1998 and Douglas, 2010).

Alternative assessment is an ongoing process of teaching and assessing students' English language learning skills in a non-threatening environment. Alternative assessment enables teachers to notice, attend to, appreciate and acknowledge each student's real potentialities. This can be ensured only if teachers are involved in continuing professional development that includes both child psychology and current English language teaching practices. If teachers consider the professional ethics and make use of available teaching resources and materials, they will build a habit of taking classroom notes and maintaining systematic observation. This will eventually lead to reliable and valid 
assessment practices in English classrooms. Teachers should avoid "onesize-fits-all" approach while dealing with young learners and investigate ample opportunities to enhance students' learning achievements. Alternative assessment approaches help to make decisions based on students' learning on the basis of the evidences collected throughout the classroom performances.

Alternative assessment is beneficial not only to teachers but also students and parents. Teachers practise self-assessment and a reflective approach to strengthen their teaching standards, while students get miscellaneous platforms to showcase their strengths, work on the areas to improve their learning. Students become self-motivated and autonomous learners. Parents are aware of their children's progress, ways to track and share relevant concerns, and issues regarding their learning performances at home, which eventually help them to contribute towards their children's overall development. However, Sutton (1992) states that the challenge is to find a process that illuminates rather than removes the uniqueness of the child and provides "feed-forward" as well as "feed-back" to help all recipients to make effective decisions about future action on the basis of the information.

To conclude, equal participation and shared responsibility among the key stakeholders viz. parents, principals, teachers, and students are crucial for the successful implementation of the alternative assessment practices in English language classrooms. The mission of schools has to be to strive for creating meaningful learning experiences in class, and promoting life skills through a wide range of class activities and outdoor programs, rather than focusing on increasing the test scores at the end of the school year. However, this study has not investigated the perspectives of students, parents and school administrations regarding the alternative assessment practices. More importantly, the data collected for this study is derived from well-resourced private schools in Kathmandu and thus the findings need to be treated with caution. Further research needs to be carried out in other less-resourced schools and contexts.

\section{About the author}

Pratistha Shrestha, holds a Master's degree in English language teaching from the Kathmandu University. She has worked in a variety of schools both private and public schools as an English language teacher and teacher educator. As a life member of NELTA, Pratistha has volunteered to conduct workshops for English language teachers. Her areas of interest include teacher development, literature and literacy.

\section{References}

Alausa, Y. A. (1996). Continuous assessment in our schools: Advantages and problems. Retrieved on 25th Nov. 2011 from http:/ / www.nied.edu.na/journal9/ JournalArticle.pdf.

Andrade, H. (2011). Promoting learning and achievement through self-assessment. Journal on Better Evidence-based Education, 3(3), 12-13. 
Black, P. \& William, D. (1998). Inside the black box: Raising standards through classroom assessment. London: GL Assessment Limited.

Black, P., Harrison, C., Lee, C., Marshall, B. \& William, D. (2002). Working inside the black box: Assessment for learning in the classroom. London: GL Assessment Limited.

Bolyard, K. J.(2003). Linking continuous assessment and teacher development: Evaluating a model of continuous assessment for primary schools in Malawi. Retrieved on 25th Nov. 2011 from http:/ / www.equip123.net/docs/ e1-003.pdf

Brown, J. D. \& Hudson, T. (1998). The Alternatives in Language Assessment. Journal on TESOL, 32(4), 653-675.

Cameron, L. (2001). Teaching languages to young learners. Cambridge: Cambridge University Press.

Cohen, L., Manion L. \& Morrison, K. (2008). Research methods in education (6th ed.) . London: Routledge Falmer

Coombe, C. \& Hubley, N. (2011). Fundamentals of language assessment. Retrieved on 25th Nov. 2011 from http:// www.christinecoombe.com.

Curriculum Development Center. (2008). Primary Education Curriculum. Bhaktapur:

Author

Douglas, D. (2010). Understanding language testing. London: Hodder Education.

Flick, U. (2006).An introduction to qualitative research (3rd ed.). London: Sage Publications.
Freeman, R. \& Lewis, R. (2005). Planning and implementing assessment. London: Routledge Falmer.

Ghaith, G. (2002). Using cooperative learning to facilitate alternative assessment. English Teaching Forum, 40(3),26-31.

Heritage, M. (2011). Formative assessment: An enabler of learning. Journal on Better: Evidence-based Education, 3(3),18-19.

Higgins, S. (2011). Formative assessment and feedback to learners. Journal on Better: Evidence-based Education, 3(3), 8-9.

Higher Secondary Education Board (2011).Examination reforms and continuous and comprehensive evaluation system in higher secondary education board (HSEB) and for proposed national examination board (NEB). Retrieved on 25th Nov. 2011 from http:// www.hseb.edu.np.

Huerta-Macias, A. (1995). Alternative assessment: Responses to commonly asked questions. TESOL Journal: Special Issue Alternative Assessment, 5(1), 8-11.

Khaniya, T. R. (2005). Examination for enhanced learning. Lalitpur: Millennium Publication (P) Ltd.

Lafi, T. (2002). Alternatives assessment. Republic of Tunisia: Ministry of Education. Retrieved on 25th Nov. 2011 from http:// www.anglais.edunet.tn/tutorials/elt

Larsen-Freeman, D. (2010).Techniques and principles in language teaching. Oxford: Oxford University Press. 
Law, B. \& Eckes, M. (2007). Assessment and ESL: An alternative approach (2nd ed.). Canada: Portage \& Main Press.

O’Malley, J. M. \& Pierce, L. V. (1996). Authentic assessment for English language learners. USA: AddisonWesley Publishing Company.

Parajuli, T.R. (2003). Effect of CAS on students' achievement, dropouts and attendance (Final Report). Curriculum Development Centre: Bhaktapur.

Puppin, L. (2007). A paradigm shift: From paper-and-pencil tests to performance-based assessment. English Teaching Forum, 45 (4),10-17.

Richards, K. (2003). Qualitative inquiry in TESOL. New York: Palgrave Macmillan
Richards, J.C., \& Rodgers, T.S. (2010). Approaches and methods in language teaching. Cambridge: Cambridge University Press

Shepard, L. (2005). Assessment (pp.275326). In L., Darling- Hammond \& J.,

Bransford (Eds.). Preparing teachers for a changing world. San

Francisco: Jossey-Bass Publishers.

Spendlove, D. (2011). Putting assessment for learning into practice. London:

Continuum International Publishing House.

Sutton, R. (1992). Assessment: A framework for teachers. London: Routledge

Appendix A

Respondents' Background

\begin{tabular}{|l|c|c|c|c|c|}
\hline \multirow{2}{*}{ Respondents } & Qualification & $\begin{array}{c}\text { Teaching Experience } \\
\text { Use of paper- } \\
\text { pencil tests }\end{array}$ & $\begin{array}{c}\text { Use of } \\
\text { alternative } \\
\text { assessment }\end{array}$ & $\begin{array}{c}\text { On-the-job } \\
\text { training related to } \\
\text { assessment }\end{array}$ & $\begin{array}{c}\text { Had the concept of } \\
\text { alternative } \\
\text { assessment before } \\
\text { joining the current } \\
\text { school }\end{array}$ \\
\hline Respondent 1 & $\begin{array}{c}\text { B.Ed. English } \\
\text { 2nd Year }\end{array}$ & - & 11 years & Yes & No \\
\hline Respondent 2 & B.Ed. English & 20 years & 1 year & Yes & No \\
\hline Respondent 3 & BBS & 2 years & 7 years & Yes & No \\
\hline Respondent 4 & $\begin{array}{c}\text { M.Ed. in } \\
\text { English }\end{array}$ & - & 8 years & Yes & Yes \\
\hline Respondent 5 & $\begin{array}{c}\text { M.A. in English } \\
\text { Literature }\end{array}$ & 11 years & 3 years & Yes & No \\
\hline Respondent 6 & $\begin{array}{c}\text { M.A. in English } \\
\text { Literature }\end{array}$ & - & 16 years & Yes & No \\
\hline
\end{tabular}

